\title{
Basal cell adenocarcinoma of the tongue-A rarity Case report
}

${ }^{1}$ Department of Oral Medicine and Radiology, A. B. Shetty Memorial Institute of Dental Sciences, Nitte University

\begin{abstract}
Basal cell adenocarcinoma is an unusual basaloid tumour that usually affects the parotid and very rarely involves the submandibular or minor salivary glands. It constitutes $1.6 \%$ of all salivary gland tumours and occurs as an asymptomatic freely mobile mass with occasional lymph node metastasis. Differentiation from benign salivary gland tumours like basal cell adenoma is accomplished by determining the depth of tumour invasion and patterns of growth or infiltration. Although it is categorised as a low-grade malignancy, it has a high propensity for recurrence. Surgical excision with a wide margin is the preferred course of treatment with radiotherapy being reserved only for tumours of the minor salivary glands with a diffuse pattern of infiltration. We present here a case of basal cell adenocarcinoma with a rare presentation in the minor salivary glands of the tongue which arose from a previously treated basal cell adenoma in the same site.
\end{abstract}

Keywords: Adenocarcinoma, Basaloid Tumour, Minor Salivary Gland

\section{Ananya Madiyal}

Department of Oral Medicine and Radiology

A. B Shetty Memorial Institute of Dental Sciences, Nitte University Deralakatte, Mangalore-575018

email : ananyamadiyal@gmail.com phone: +919538840189

\section{Introduction}

World Health Organisation (WHO) classified basal cell adenocarcinoma (BCAC) as a salivary gland tumour in 1991 and in 2005 categorised it as a low-grade malignancy [1]. Historically it has been termed under several names such as malignant basal cell adenoma, carcinoma ex monomorphic adenoma and basaloid salivary carcinoma [2]. Although some researchers claim that the lesion arises from previously existing basal cell adenoma while others claim that it arises de novo, the exact histogenesis is still unknown [1].

Basal cell adenocarcinoma is seen in older adults with a mean age of 58 years [3]. Some researchers claim a slight male preponderance while others claim that the lesion affects both genders equally $[1,4]$. $3-4 \%$ of all head and neck tumours are salivary gland tumours. BCAC constitutes $1.6 \%$ of these salivary gland tumours and $29 \%$ of all malignant salivary gland tumours. A vast majority $(90 \%)$ of BCAC originate from the parotid glands while submandibular and minor salivary gland $\mathrm{BCAC}$ make up a small percentage $[1,5,6]$. When the parotid is involved, it is usually seen in the superficial lobe of the gland [7]. We present here a rare case of basal cell adenocarcinoma of the tongue that arose from a previously treated basal cell adenoma of the minor salivary gland in an elderly female. 


\section{Case Report}

A 60 years old female patient reported with a complaint of a slowly growing painless swelling in the left side of the tongue since six months. The patient had a history of excision of a similar lesion at the same site one year ago which had been diagnosed histopathologically as basal cell adenoma. There were no abnormalities detected on extra-oral examination. Intra-oral examination revealed an ulceroproliferative lesion measuring approximately $4 \times 3 \mathrm{~cm}$ in size was seen on the left posterolateral aspect of the tongue. The surface contained indentations from the posterior teeth and was covered with slough (Figure 1). The lesion was soft, non-tender and mobile. A provisional diagnosis of recurrence of basal cell adenoma as well as basal cell adenocarcinoma was considered. Radiographic examination with panoramic imaging showed no bony changes.

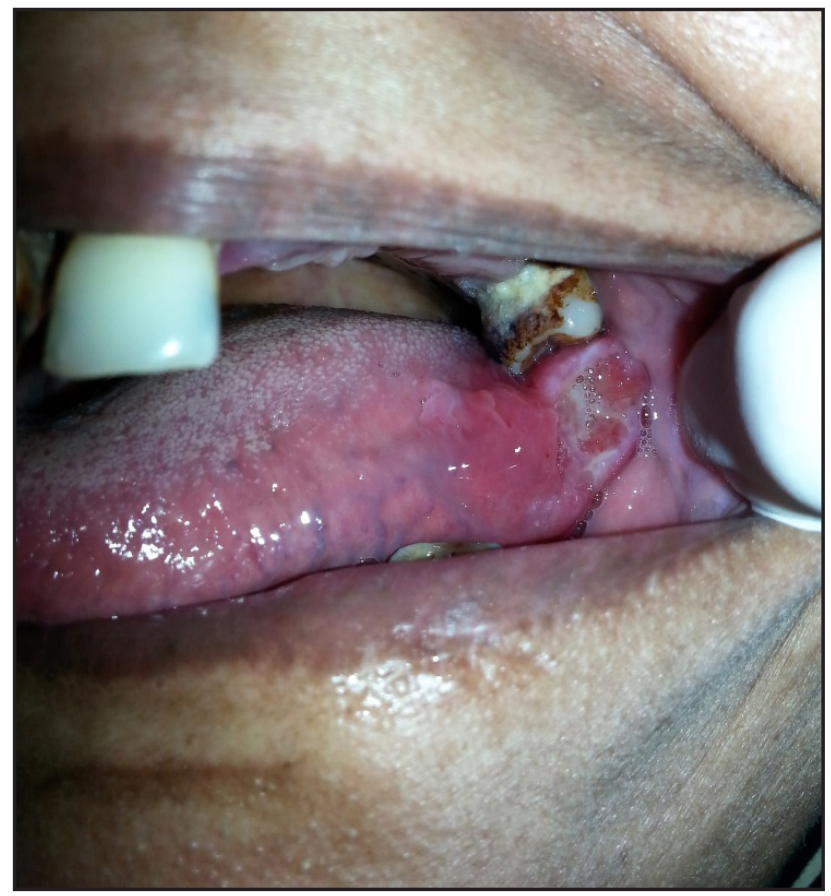

Figure 1: Intra-oral view of the patient showing an ulceroproliferative lesion in the left posterolateral aspect of the tongue.
The lesion was excised with wide margins. Haematoxylin and eosin stained sections showed groups of basaloid type of epithelial cells proliferating into connective tissue in the form of tubular, canalicular and solid islands. The tumour cells showed two types of morphologies; with one cell type being larger and showing vesicular nuclei while other cell type was smaller in size and showed hyperchromatic nucleus and minimal cytoplasm. Few islands showing peripheral cells with palisading hyperchromatic nuclei were seen. Few islands with central necrosis were also seen. Some areas contained clear cells in organoid configuration while in certain areas the tumour cells showed pleomorphism and high mitotic activity. Tumour cells were seen infiltrating the muscle fibres along with perineural infiltration. Connective tissue showed hyalinised collagen fibres. All surgical margins appeared to be free from malignancy. The histological impression was that of basal cell adenocarcinoma (Figure 2). Immunohistochemistry showed that S100 was focally positive in the cells and Ki67 proliferation index was $3-4 \%$. The patient was kept under routine follow-up and has been disease free for the last two years.

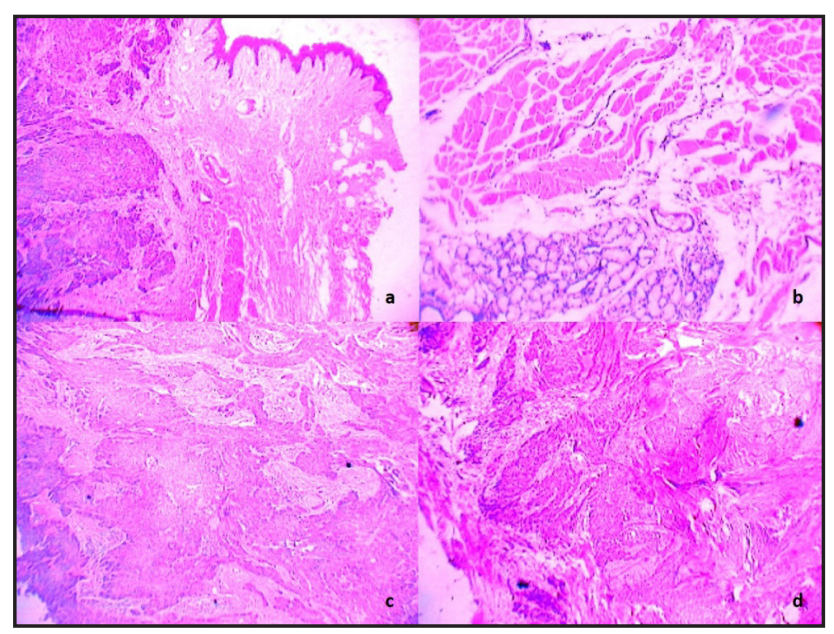

Figure 2: Photomicrograph showing histologic features of basal cell adenocarcinoma. 


\section{Discussion}

Basal cell adenocarcinoma was first described in 1978 and the histological features were described in 1988 by Ellis and Gnepp. Later in 1990 Ellis and Wiscivitch described the clinical and pathological features of the lesion $[5,7]$. BCAC is a rare salivary gland neoplasm with an unknown etiology, although some researchers claim that the tumour arises from pluripotent ductal epithelial cells or from reserve cells $[1,5,6]$. While a small portion of the lesions present with pain or tenderness, a vast majority occur as asymptomatic freely moveable swelling with a time period before diagnosis ranging from weeks to years. Pisharodi et al found that tumour size ranged from $0.7 \mathrm{~cm}$ to $4 \mathrm{~cm} \mathrm{[4].}$

It is often difficult to differentiate $\mathrm{BCAC}$ from its benign counterpart, basal cell adenoma (BCA) due to the low-grade malignant potential of BCAC. Diagnostic criteria include the pattern of growth and the presence of perivascular or perineural infiltration of the tumour [5]. The lesion is diagnosed as BCAC in the presence of infiltration into periglandular fat, muscle, parotid parenchyma or dermis, cellular atypia, necrosis and mitosis [1,2]. The present case showed infiltration into the connective tissue, muscle fibres and nerves, tumour islands with central necrosis, pleomorphism and high mitotic activity thereby leading to its diagnosis as basal cell adenocarcinoma.

Macroscopically, the cut surface of the tumour is brown, grey or tan-white in colour with areas of cystic degeneration and infiltration [3]. Microscopically, WHO has classified BCAC into solid, tubular, membranous and trabecular patterns [1]. The solid pattern which is the most common, consists of varying numbers of islands separated by thin septae or thick collagenous bands. The tubular type consists of basaloid cells with interspersed luminal spaces. The membranous type is characterised by large amount of PAS positive, hyalinised eosinophilic basal lamina that forms the peripheral membrane and intercellular droplets. The trabecular type contains basaloid cells that form interconnecting bands [5]. Andraedis et al found that both $\mathrm{BCA}$ and $\mathrm{BCAC}$ had similar architectural and cytologic factors and were not differentiable by ultrastructural or immunohistochemical examinations [8]. However, other researchers have found certain immunohistochemical markers that may play a role in the diagnosis of BCAC (Table I) [3,4,5].

Table I: Table showing immunohistochemical markers used for the diagnosis of basal cell adenocarcinoma.

\begin{tabular}{|l|l|}
\hline $\begin{array}{l}\text { Immunohistochemical } \\
\text { Markers }\end{array}$ & Diagnostic Criteria \\
\hline Cytokeratin (CK) 7 & Focal strong positive \\
\hline Cytokeratin (CK) 20 & $\begin{array}{l}\text { Negative or focal weak } \\
\text { positive }\end{array}$ \\
\hline $\begin{array}{l}\text { Carcinoembryonic } \\
\text { antigen (CEA) }\end{array}$ & Positive \\
\hline $\begin{array}{l}\text { Epithelial membrane } \\
\text { antigen (EMA) }\end{array}$ & Positive \\
\hline $\begin{array}{l}\text { S100 } \\
\text { Glial fibrillary acidic } \\
\text { protein }\end{array}$ & $\begin{array}{l}\text { Moderate to strong positive } \\
\text { in myoepithelial cells }\end{array}$ \\
\hline Smooth muscle actin & Negative \\
\hline p53 & Moderate staining \\
\hline Bcl-2 & Strong positive \\
\hline
\end{tabular}

It is important to distinguish BCAC from other lesions such as basal cell adenoma, basaloid squamous cell carcinoma, myoepithelial lesions, Warthin tumour, pleomorphic adenoma, small cell undifferentiated carcinoma, metastatic adenocarcinoma and adenoid cystic carcinoma due to the difference in treatment and prognosis among these lesions $[3,4,5,9]$. On $\mathrm{T} 1$ and $\mathrm{T} 2$ weighted magnetic resonance images, basal cell adenoma appears well circumscribed with multiple endothelial lined channels while adenoid cystic carcinoma shows extensive invasion without vascularity in the microcysts. Warthin tumour shows intermediate signal intensity in both $\mathrm{T} 1$ and T2 weighted images while pleomorphic adenoma shows heterogenous intermediate signal intensity in $\mathrm{T} 1$ weighted images and high intensity signals in T2 weighted images [9]. Although slow growing, BCAC shows local invasion and recurrence in $25-30 \%$ of the cases and metastasis to lymph nodes in $10 \%$ of the affected individuals $[1,5,10]$. Surgical excision 
with wide margins is the preferred treatment with radiotherapy being instituted for tumours involving the minor salivary glands with diffuse infiltration [1].

Basal cell adenocarcinoma is usually seen in the superficial lobe of the parotid and only rarely involves the minor salivary glands. Minor salivary gland involvement is typically seen in the hard palate. Literature with involvement of areas such as buccal mucosa and tongue is very scarce $[5,11,12]$. We present here a case of basal cell adenocarcinoma of the minor salivary glands in an unusual location arising from a previously treated basal cell adenoma with a hope to increase the body of literature regarding this rare entity.

\section{Conclusion}

Basal cell adenocarcinoma is a relatively rare salivary gland tumour that occurs in older adults. Very little information is available regarding these tumours when they arise from minor salivary glands. It is important to distinguish BCAC from its benign counterpart and also from other basaloid tumours of salivary glands in order to ensure that the right treatment protocol is observed. Due to the high propensity for recurrence of the tumour, patients should be advised regarding the need for periodic recall visits in order to avoid the morbidity and mortality associated with undiagnosed lesions.

\section{References}

1. Akhtar K, Zaidi N, Ara A, Sherwani RK. (2014). Basal cell adenocarcinoma of the parotid and its simulating differentials- A case report. JMED Research. Article ID 778687, DOI: 10.5171/2014.778687.
2. Sulakshana MS, Deepti SP, Dayananda BS. (2015). Basal cell adenocarcinoma of the salivary gland- A rare entity. IAIM. 2(5), 156-9.

3. Farrell T, Chang YL. (2007). Basal cell adenocarcinoma of minor salivary glands. Arch. Pathol. Lab. Med. 131, 1602-4.

4. Pisharodi LR. (1995). Basal cell adenocarcinoma of the salivary gland. Diagnosis by fine-needle aspiration cytology. Am. J. Clin. Pathol. 103(5), 603-8.

5. Gupta G, Singh R, Shanmugasamy K, Kotasthane DS, Kotasthane VD. (2010). Basal cell adenocarcinoma in the tongue: An unusual presentation. Clin. Med. Insights. Oncol. 4, 127-31.

6. Veeresh $\mathrm{M}$, Bavle RM, Vinay $\mathrm{KN}$, Nandakumar H. (2010). Basal cell adenoma of the submandibular gland. J. Maxillofac. Oral. Surg. 9(3), 289-91.

7. Ellis GL, Wiscovitch JG. (1990). Basal cell adenocarcinomas of the major salivary glands. Oral. Surg. Oral. Med. Oral. Pathol. 69, 461-9.

8. Andreadis D, Nomikos A, Epivatianos A, Poulopoulos A, Barbatis C. (2005). Basaloid squamous cell carcinoma versus basal cell adenocarcinoma of the oral cavity. Pathology. 37(6), 560-3.

9. Jang M, Park D, Lee SR, Hahm CK, Kim Y, Kim Y, Park CK, Tae K, Park MH, Park YW. (2004). Basal cell adenoma in the parotid gland: CT and MR findings. Am. $J$. Neuroradiol. 25, 631-5.

10. Scholtz A, Hollrigl A, Verdorfer I. (200). Genetic alterations in a basal cell adenocarcinoma of the glandula submandibularis [letter]. Cancer. Genet. Cytogenet. 172, 87-9.

11. Parashar P, Baron E, Papadimitriou JC, Ord RA, Nikitakis NG. (2007). Basal cell adenocarcinoma of the oral minor salivary glands: Review of the literature and 
presentation of two cases. Oral. Surg. Oral. Med. Oral. Pathol. 103(1), 77-84.

12. Luna M, Batsakis JG, Tortoledo ME, del Junco GW. (1989). Carcinomas exmonomorphic adenoma of salivary glands. J. Laryngol. Otol. 103, 756-9. 